\title{
(2) OPEN ACCESS \\ Cohort effects of tobacco control policy: evidence to support a tobacco-free norm through smoke-free policy
}

\author{
Heewon Kang $\odot$, ' Sung-il Cho ${ }^{1,2}$
}

\begin{abstract}
- Additional material is published online only. To view please visit the journal online (http://dx.doi.org/10.1136/ tobaccocontrol-2018-054536).

${ }^{1}$ Department of Public Health Science, Graduate School of Public Health, Seoul National University, Seoul, Korea ${ }^{2}$ Institute of Health and Environment, Seoul National University, Seoul, Korea
\end{abstract}

\section{Correspondence to}

Dr Sung-il Cho, Department of Public Health Science, Graduate School of Public Health, Seoul National University, Seoul 151 742, Korea; persontime@hotmail.com

Received 4 June 2018 Revised 10 November 2018 Accepted 1 December 2018 Published Online First 15 December 2018

\begin{abstract}
Background The prevalence of cigarette smoking among South Korean adolescents has decreased markedly over the past decade, which may indicate a norm shift between generations of adolescents. The present study aims to identify the effect of banning smoking in public places and increasing cigarette prices on current adolescent smoking, and to determine whether these policies additionally resulted in cohort effects.

Methods Repeated cross-sectional survey data, nationally representative of South Korean adolescents, were used. A total of 853441 adolescents ranging in age from 12 to 18 years (mean age, 15 years) were identified. Models applied were segmented regression model to detect changes in smoking trends and ageperiod-cohort model to determine the cohort effects on the trends.
\end{abstract}

Findings Between 2006 and 2017, smoking decreased from $16 \%$ to $9 \%$ in boys and from $9 \%$ to $3 \%$ in girls. After a complete ban on smoking in public places, there were significantly negative trends in the prevalence of smoking for both boys ( $\beta=-1.1 ; 95 \% \mathrm{Cl}:-1.9$ to -0.2$)$ and girls ( $\beta=-0.4 ; 95 \% \mathrm{Cl}:-0.6$ to -0.1$)$. Immediate decrease among girls was found after cigarette prices increased ( $\beta=-0.8 ; 95 \% \mathrm{Cl}:-1.5$ to -0.2$)$. For the cohort effect, the risk of smoking decreased with every consecutive year for boys born after 1998 and girls born after 1997.

Conclusions Our results indicate the presence of cohort effects in the reduction of adolescent smoking. The cohort effect was induced by smoke-free legislation. Research on cohort effects, and methods to denormalise tobacco, will contribute to preventing adolescents from ever trying a cigarette.

\section{INTRODUCTION}

Achieving a tobacco-free world depends largely on the prevention of tobacco use among young generations. Although adolescents' tobacco use has been decreasing globally since the early 2000 s, $^{1}$ it is still a major public health concern, as it is a strong predictor of continued smoking in adulthood and future detrimental health outcomes. ${ }^{2}$ Among the wide range of interventions that help reduce adolescent tobacco use, a key measure is reinforcing the public perception that tobacco use is not a mainstream activity in society, that is, denormalisation. ${ }^{3}$

Efforts to denormalise tobacco use have resulted in substantial reductions of smoking at a population-level, including youths. ${ }^{4-7}$ Key approaches to tobacco denormalisation include limiting the locations available to smoke in, increasing the prices of tobacco products and controlling how tobacco products are sold and advertised. ${ }^{3}$ Although changing social norms is generally the main goal of tobacco control policies, ${ }^{8}$ it is difficult to directly obtain an objective measure of social norms in a population. The 'cohort effect', that is, the changes across different generations, can be used to detect shifts in social norms which are predominantly formed among those within the same generational group. ${ }^{9}$

Each new generation or cohort have unique experiences that provide an opportunity for societal transformation, ${ }^{9}$ such as a world free of tobacco use. This is because cohort membership formed during adolescence endures throughout the rest of life. ${ }^{10}$ In addition, assessing cohort effects can help elucidate the impact of macroenvironmental events through studying the responses to shared exposure among a group of individuals, during a certain period. Furthermore, the presence of cohort effects in smoking trends raises an important methodological issue. Cross-sectional studies, such as the Global Youth Tobacco Survey, often examine smoking behaviours using agespecific or year-specific statistics, ${ }^{11}$ but these indicators can be confounded by changes in age composition or the timing of policies. ${ }^{12}$ Thus, trends should be studied within the context of birth cohorts, and the investigation of cohort effects with regard to tobacco control is particularly important.

In South Korea, comprehensive tobacco control measures began with the enactment of the Health Promotion Act in 1995. This act prohibits tobacco sales to minors; restricts tobacco sales, smoking in some public places through the designation of smoke-free areas and tobacco advertising, promotion and sponsorships; and requires textonly warning labels on cigarette packs. Since the ratification of the Framework Convention on Tobacco Control (FCTC) in 2005, additional tobacco control policies have been introduced and strengthened (figure 1).

During the post-FCTC period, smoking prevalence among South Korean adolescents declined markedly, from $12.8 \%$ in 2006 to $6.4 \%$ in 2017. This population-level decrease indicates presence of a significant transition in social norms among generations of youths. Two important components of the tobacco control legislation in South Korea that contributed to tobacco denormalisation ${ }^{6}$ were the banning of smoking in public places in 
Landmarks of tobacco control policies in South Korea
Landmarks of tobacco control policies particularly targeting adolescents

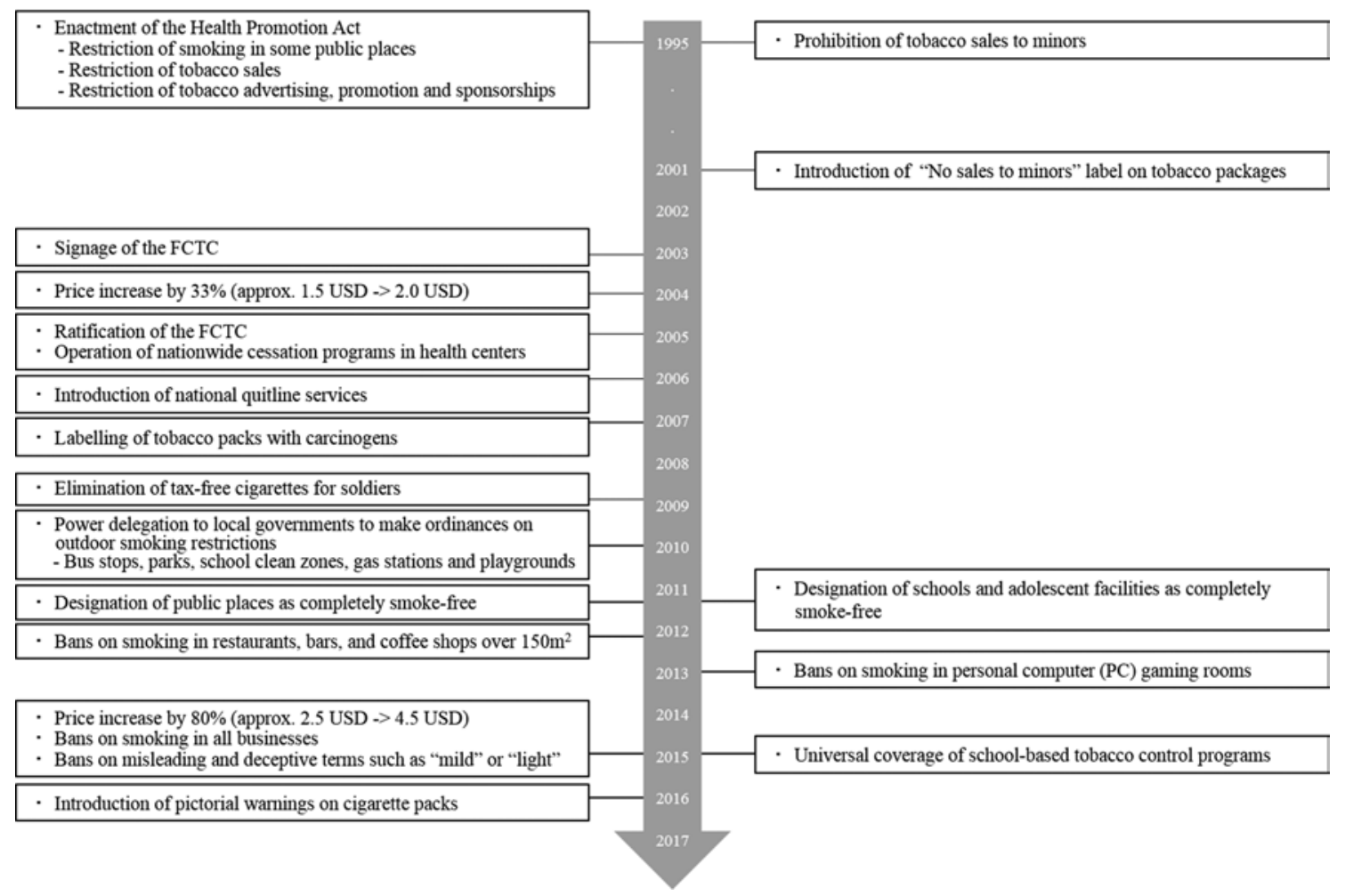

Figure 1 Landmarks of tobacco control policies in South Korea. FCTC, Framework Convention on Tobacco Control.

December 2011, and the largest ever increase in cigarette prices $(2500 \mathrm{WON} /$ pack $\rightarrow 4500 \mathrm{WON} /$ pack$)$, in January 2015.

Prior studies have yielded favourable impacts of smoke-free legislation and price increase on adolescent smoking prevalence and frequency. ${ }^{13-15}$ For example, Hawkins et $a l^{14}$ emphasised that youngest adolescents were most sensitive to prices, while smokefree legislation was effective in all age groups. One limitation of these studies is that age-related changes represent mixed effects of birth cohort and age on adolescent smoking. Therefore, we investigated whether these policies contributed to the observed decline in adolescent smoking prevalence, particularly through lasting effects on different cohorts that goes beyond declining trends in all age groups. The presence of cohort effects as a result of tobacco control policy would indicate the likelihood of social norms trending towards a generation where tobacco use is not the norm.

Using segmented regression and age-period-cohort (APC) analysis, this study seeks to (1) determine whether the implementation of smoke-free legislation in public places and the increase in cigarette prices were associated with reductions in cigarette use in adolescents of all ages and (2) whether these policies resulted in cohort effects that lowered cigarette smoking prevalence beyond that expected from the decreasing trends alone.

\section{METHODS}

\section{Study design and participants}

Data were acquired from the Korea Youth Risk Behavior Webbased Survey (KYRBS) which has been conducted nationwide every year since 2005 by the Korea Centers of Disease Control and Prevention. KYRBS is a self-report, anonymous and repeated cross-sectional survey monitoring health-related behaviours among middle and high school students in South Korea. A multistage cluster sampling design was used to obtain representative samples of South Korean adolescents aged 12-18 enrolled in secondary schools. A more detailed description of KYRBS is provided elsewhere. ${ }^{16}$ Data from the first survey in 2005 were excluded from the analysis because 12th graders were not surveyed due to a scheduled national college examination. Between 2006 and 2017, the total number of respondents was 859815 and the average sample size per year was 71651 . The overall response rate during the study period was high, at $95.9 \%$. Response rates were more than 95\% throughout the study period except in 2006 and 2007, when they were $90.9 \%$ and $94.8 \%$, respectively. Those who had not reported their age in the survey were excluded since age is one of the main dimensions in APC analyses. Approximately 500 adolescents per year were excluded from the data analysis. The number of subjects included in the final analysis was 853441 . The sampling design and measures of cigarette smoking were consistent throughout the study period.

\section{Identification of cigarette smoking prevalence}

Adolescent cigarette smokers were defined by the question 'During the past 30 days, how many days did you smoke cigarettes, even one cigarette?' Those who answered ' 1 to 2 days', ' 3 to 5 days', ' 6 to 9 days', ' 10 to 19 days', '20 to 29 days' or 'everyday' in response to this question were identified as current cigarette smokers.

\section{Statistical analysis}

Segmented regression analysis

Segmented regression analysis of an interrupted time-series is a powerful tool for investigating the effects of time-delimited 
natural experiments. ${ }^{17}$ Impacts on the metric of interest resulting from an intervention are estimated by assessing the levels and trends of the metric in the preintervention and postintervention segments. ${ }^{17}$

In this study, an exploratory analysis prior to statistical modelling was undertaken through the calculation of year-specific prevalence of cigarette smoking by sex, using weighted counts of current smokers. Age-standardised and perceived household wealth (high/middle/low)-standardised prevalence of cigarette smoking was then obtained using the distribution of the 2006 KYRBS sample, to detect changes in the level and trend of cigarette smoking prevalence following the introduction of the smoke-free legislation in December 2011, and the price increase in January 2015. The model used was:

$$
\begin{aligned}
P_{t}= & \beta_{0}+\beta_{1} * \text { time } e_{t}+\beta_{2} * \text { intervention } 1_{t}+ \\
& \beta_{3} * \text { time after intervention } 1_{t}+\beta_{4} * \text { intervention } 2_{t}+ \\
& \beta_{5} * \text { time after intervention } 2_{t}+e_{t}
\end{aligned}
$$

where $P_{t}$ is the prevalence of smoking in year $\mathrm{t}, \beta_{0}$ is estimated baseline smoking prevalence before the beginning of the study period, $\beta_{1}$ is the baseline trend, $\beta_{2}$ is the immediate change in smoking prevalence following the introduction of the smokefree legislation for public places, $\beta_{3}$ is the slope change after smoke-free legislation was implemented, $\beta_{4}$ is the estimate of the immediate change in smoking prevalence following the price increase and $\beta_{5}$ is the slope change after the price increase. The Durbin-Watson statistic was used to test for possible autocorrelation of the residuals. ${ }^{17}$ All analyses related to segmented regression were conducted using STATA/IC V.15. ${ }^{18}$

\section{APC analysis}

As the cohort is determined by age and period (cohort=periodage), cohort effects can be obtained through the application of an APC model. In this study, the sex-stratified, age-specific prevalence of cigarette smoking was modelled as a function of age, period and cohort. The APC model was assumed to follow a Poisson distribution and was fitted using a log-link function. Age was classified in single years from 12 to 18 years and period covered 12 survey years from 2006 to 2017. As a factor corresponding to the age groups and time periods, 18 birth cohorts from 1988 to 2005 were identified. The general formula of an APC model for log age-specific rates $\lambda(a, p)$ at age $a$ in period $p$ for persons in cohort $\mathrm{c}=\mathrm{p}-\mathrm{a}$ is: $\log [\lambda(a, p)]=f(a)+g(p)+h(c)$.

To manage the non-identifiability issue arising from the exact linear dependence of the three factors, ${ }^{9}$ we applied the intrinsic estimator (IE) method which introduces principal component analysis. The IE method uses constraints that are less subjective and yields smaller variances in estimated coefficients compared with conventional constraint models. ${ }^{19}$

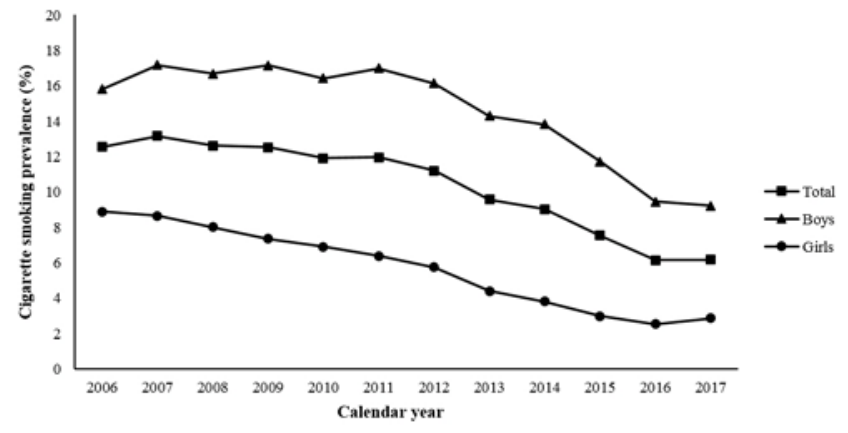

Figure 2 Prevalence of cigarette smoking among South Korean adolescents, 2006-2017.

Results from APC analysis are more related to changes in aggregated data due to cohort effects than to the aetiology of the changes. ${ }^{20}$ Thus, to understand the mechanism underlying cohort effects, additional analyses using the APC characteristics model, ${ }^{21}$ and yearly changes in smoking initiation and cessation, were conducted (online supplementary file 1).

All statistical analyses were performed using STATA/IC V.15, ${ }^{18}$ and graphical visualisation was performed in $\mathrm{R}^{22}$ The derived coefficients and CIs were exponentiated to obtain prevalence rate ratios (PRRs).

\section{RESULTS}

\section{Prevalence of cigarette smoking}

We used data from 853441 adolescents (439783 boys (52\%) and 413658 girls (48\%)) over the study period of 2006 to 2017 in our analyses. Trends in the prevalence of adolescent cigarette smoking are displayed in figure 2. Smoking prevalence (unadjusted) among South Korean adolescents remained steady between 12\% and 13.2\% from 2006 to 2011. Then, from 2011 to 2017 , a decrease in smoking prevalence from $12 \%$ to $6.2 \%$ was observed. For boys, smoking prevalence fluctuated between $15.8 \%$ and $17.2 \%$ during 2006-2011. Smoking prevalence in boys then decreased from $17.0 \%$ in 2011 to $9.2 \%$ in 2017. Among girls, the prevalence of smoking decreased gradually from $8.9 \%$ in 2006 to less than $3 \%$ in 2016 . However, the most recent statistics in 2017 indicate that smoking among girls is on the rise.

\section{Segmented regression model}

The patterns of sex-stratified, age-adjusted and perceived household wealth-adjusted current cigarette use based on

\begin{tabular}{|c|c|c|c|c|c|c|c|c|}
\hline & \multicolumn{4}{|l|}{ Boys } & \multicolumn{4}{|l|}{ Girls } \\
\hline & \multirow[b]{2}{*}{$\boldsymbol{\beta}$} & \multicolumn{2}{|l|}{$95 \% \mathrm{Cl}$} & \multirow[b]{2}{*}{$P$ value } & \multirow[b]{2}{*}{$\boldsymbol{\beta}$} & \multicolumn{2}{|l|}{$95 \% \mathrm{Cl}$} & \multirow[b]{2}{*}{$P$ value } \\
\hline & & Lower & Upper & & & Lower & Upper & \\
\hline Baseline trend $\beta_{1}$ & -0.1 & -0.3 & 0.2 & 0.610 & -0.6 & -0.6 & -0.5 & $<0.001$ \\
\hline Level change after smoke-free legislation $\beta_{2}$ & 0.8 & -1.1 & 2.7 & 0.406 & 0.4 & -0.3 & 1.0 & 0.255 \\
\hline Trend change after smoke-free legislation $\beta_{3}$ & -1.1 & -1.9 & -0.2 & 0.013 & -0.4 & -0.6 & -0.1 & 0.011 \\
\hline Trend change after price increase $\beta_{5}$ & -0.1 & -1.3 & 1.0 & 0.795 & 0.9 & 0.5 & 1.2 & $<0.001$ \\
\hline
\end{tabular}
segmented regression analysis are summarised in table 1 . No

Table 1 Result of the segmented regression model predicting smoking prevalence by sex 


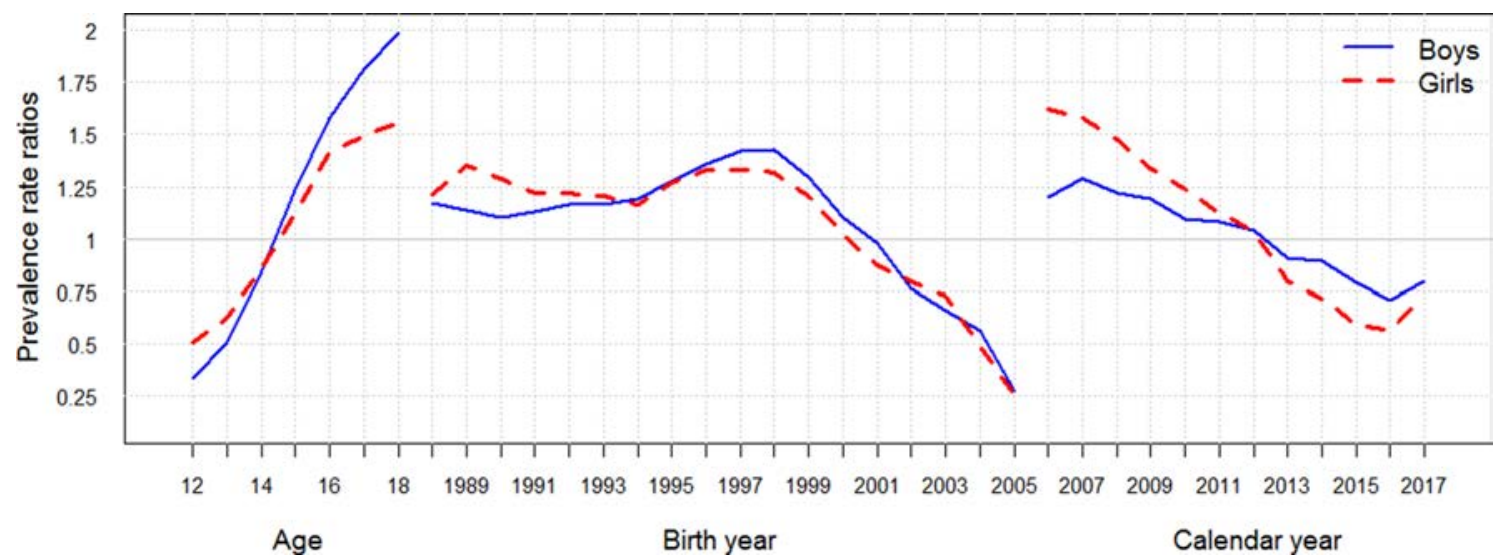

Figure 3 Estimated age-period-cohort effects for cigarette smoking prevalence.

significant autocorrelation was observed using the DurbinWatson test. For boys, no significant trends in smoking prevalence were observed during the baseline period of 2006-2011, with $\beta=-0.1$ (95\% CI: -0.3 to 0.2$)$. The implementation of the legislation on smoke-free public places in December 2011 did not immediately lead to significant level changes in smoking prevalence $(0.8 ; 95 \% \mathrm{CI}$ : -1.1 to 2.7$)$, but there was a significant decreasing trend $(-1.1 ; 95 \% \mathrm{CI}:-1.9$ to $-0.2)$. The increase in cigarette prices in 2015 did not lead to a significant change in level $(-1.3 ; 95 \% \mathrm{CI}:-3.3$ to 0.7$)$ or an additional decrease in the trend $(-0.1 ; 95 \% \mathrm{CI}:-1.3$ to 1.0$)$ by the end of the study period in 2017 .

Among girls, a decreasing trend in smoking prevalence $(-0.6$; 95\% CI: -0.6 to -0.5$)$ was observed during the baseline period of 2006-2011. After smoking in public places was banned in December 2011, no significant level change in smoking prevalence was observed, $(0.4 ; 95 \% \mathrm{CI}$ : -0.3 to 1.0$)$, but there was a significantly decreasing trend $(-0.4 ; 95 \% \mathrm{CI}$ : -0.6 to -0.1$)$. Increasing cigarette prices in 2015 did lead to an immediate decrease in smoking prevalence $(-0.8 ; 95 \% \mathrm{CI}$ : -1.5 to -0.2$)$, but not to a decrease in the slope of the segment $(0.9 ; 95 \% \mathrm{CI}$ : 0.5 to 1.2 ), until the end of the study period.

\section{APC model}

The full APC (IE) model provided the best fit for both sexes (online supplementary table S2 in supplementary file 1). Figure 3 presents the model-derived effect of all three parameters, age, period and cohort, on the prevalence of adolescent cigarette smoking. A progressive increase in smoking prevalence with increasing age was found in both sexes. Although the patterns were similar between the sexes, the magnitude of the age effect was observed to be larger in boys than in girls.

The period effect of adolescent cigarette use was also significant. Among boys, an estimated decrease in risk of approximately $40 \%$ was observed followed by a period of fluctuation between 2006 and 2008. The period effect was larger for girls, with the estimated PRR decreasing by more than $50 \%$.

Cohort effect in the mid-panel of figure 3 and table 2 was most striking among the three effects of the APC model. An increase in the risk of smoking was observed from 1994 to 1998, followed by a decrease from 1998 to 2005 for boys, indicating a cohort effect. From 1998 onwards, the risk of cigarette use declined across every consecutive birth year for boys. Similarly for girls, the PRRs increased from 1994 to 1997 . The risk of cigarette use also declined yearly for girls born between 1997 and 2005. The peak PRR from 1994 onwards was higher, and the association between birth year and smoking prevalence stronger, for boys than for girls.

\section{DISCUSSION}

This study illustrated the impact of two tobacco control policies, smoke-free legislation in public places, including schools and increasing cigarette prices, by applying segmented regression and APC models to a nationally representative sample of adolescents. Our results suggest that the decrease in prevalence of adolescent cigarette smoking seen for both sexes was associated with smoke-free legislation. The prevalence of cigarette smoking decreased immediately after the increase in prices, although statistically significant only in girls. The decline in cigarette smoking prevalence was influenced by birth cohort, as the risk of cigarette smoking decreased every consecutive year for those born after 1998 .

Table 2 Estimated cohort effects for cigarette smoking prevalence by sex

\begin{tabular}{|c|c|c|c|c|c|c|}
\hline \multirow[b]{3}{*}{ Cohort } & \multicolumn{3}{|l|}{ Boys } & \multicolumn{3}{|l|}{ Girls } \\
\hline & \multirow[b]{2}{*}{ PRRs } & \multicolumn{2}{|l|}{$95 \% \mathrm{Cl}$} & \multirow[b]{2}{*}{ PRRs } & \multicolumn{2}{|l|}{$95 \% \mathrm{Cl}$} \\
\hline & & Lower & Upper & & Lower & Upper \\
\hline 1988 & 1.17 & 1.03 & 1.33 & 1.21 & 1.19 & 1.23 \\
\hline 1989 & 1.13 & 1.04 & 1.24 & 1.35 & 1.34 & 1.36 \\
\hline 1990 & 1.10 & 1.02 & 1.19 & 1.29 & 1.28 & 1.30 \\
\hline 1991 & 1.13 & 1.05 & 1.22 & 1.22 & 1.21 & 1.23 \\
\hline 1992 & 1.16 & 1.08 & 1.25 & 1.22 & 1.21 & 1.23 \\
\hline 1993 & 1.16 & 1.08 & 1.25 & 1.20 & 1.20 & 1.21 \\
\hline 1994 & 1.19 & 1.11 & 1.29 & 1.16 & 1.15 & 1.17 \\
\hline 1995 & 1.28 & 1.18 & 1.38 & 1.27 & 1.26 & 1.28 \\
\hline 1996 & 1.36 & 1.26 & 1.47 & 1.33 & 1.32 & 1.34 \\
\hline 1997 & 1.42 & 1.31 & 1.54 & 1.33 & 1.31 & 1.34 \\
\hline 1998 & 1.43 & 1.31 & 1.55 & 1.32 & 1.30 & 1.33 \\
\hline 1999 & 1.29 & 1.19 & 1.41 & 1.21 & 1.19 & 1.22 \\
\hline 2000 & 1.10 & 1.00 & 1.21 & 1.02 & 1.01 & 1.03 \\
\hline 2001 & 0.98 & 0.88 & 1.09 & 0.87 & 0.86 & 0.88 \\
\hline 2002 & 0.76 & 0.66 & 0.88 & 0.80 & 0.79 & 0.81 \\
\hline 2003 & 0.65 & 0.54 & 0.79 & 0.73 & 0.71 & 0.75 \\
\hline 2004 & 0.56 & 0.43 & 0.75 & 0.49 & 0.48 & 0.51 \\
\hline 2005 & 0.27 & 0.11 & 0.66 & 0.25 & 0.23 & 0.28 \\
\hline
\end{tabular}

PRR, prevalence rate ratio. 
In the segmented regression analysis, smoke-free legislation in public places, including schools, in December 2011 was associated with a significant decreasing trend in smoking prevalence which is in line with previous studies on adolescent smoking. ${ }^{14} 152324$ Reductions in smoking prevalence can be achieved through the designation of smoke-free areas by limiting opportunities to engage in smoking and building social pressure not to smoke. ${ }^{25} 26$

Our data fell short of showing a sustainable favourable association between increasing the price of cigarettes and a reduced prevalence of cigarette smoking. This finding may be explained by a few factors. First, the level of price increase was insufficient to result in a noticeable difference given that other policies were already in effect to reduce the prevalence of smoking. A study of South Korean adolescents in 2014 reported that the median cigarette price per pack at which adolescents intended to stop smoking was $5000 \mathrm{KRW}^{27}$ which is higher than the cigarette price of $4500 \mathrm{KRW}$ after the increase. Additionally, the acquisition of tobacco via social sources such as borrowing, sharing or stealing would have dampened the responsiveness to a price increase, ${ }^{28}$ as only about half of South Korean adolescent smokers actually buy cigarettes directly with their own money. ${ }^{29}$ Furthermore, an inadequate amount of time may have passed after the price increase to observe a statistically significant effect on smoking behaviour. Although insignificant in boys, we note that there was an immediate decrease in smoking prevalence after cigarette prices were increased.

Results from the APC analysis also illustrate the possible effects of macroenvironmental circumstances on cigarette smoking prevalence in adolescents. The positive association between age and smoking found in earlier studies was confirmed in this study. ${ }^{30-32}$ The APC model suggests secular dynamics between tobacco control policies and prevalence by period effects and importantly, explains the impact of policies on different generations of adolescents via the effects of birth cohorts.

Smoke-free legislation was associated with a long-term decrease in the prevalence of adolescent cigarette smoking, implying the presence of cohort effects. ${ }^{10}$ Different risks of adolescent smoking were found in different birth cohorts. According to the cohort analysis, likelihood of smoking declined after peaking in 1998 for boys and 1997 for girls. This decreasing trend in birth cohorts born after 1997 and 1998 indicates that, along with early initial exposure to smoke-free legislation, continued exposure to the policy helped deter adolescents from smoking.

Overall, our study shows that implementation of smoke-free legislation in public places, including schools, was the major factor reducing the prevalence of cigarette smoking in adolescents. The continued decrease in smoking prevalence can be explained by cohort effects. More than other tobacco control measures, smoke-free legislation is renowned for its ability to denormalise tobacco use. ${ }^{23}$ Since social norms are predominantly generated within a birth cohort, ${ }^{9}$ effects of smoke-free legislation in establishing the norm of a society where smoking is not conceived as the prevailing norm can be inferenced by cohort effects. Smoke-free legislation could have created a virtuous circle as the presence of fewer sensory cues of others smoking would send a powerful message of what behaviours are appropriate and expected among adolescents. ${ }^{33}$ Constructing a clear identity of a generation that has a norm of a tobacco-free environment results in a prolonged effect among the cohorts sharing this experience.

Lowered risks of smoking among cohorts born after 1998 may have arisen from exposure to smoke-free policies in public places before the age of 14 years. It appears that intervening before adolescents enter secondary education is critical in the formation of an appropriate norm. This is due to the persistency of social norms. Once norms are solidly formed, they are unlikely to change for long periods of time. ${ }^{34}$ The average age of smoking initiation in Korean adolescents is 13 years, ${ }^{35}$ and the rate of smoking initiation increases more than threefold when adolescents advance to middle school. ${ }^{36}$ An increased presence of smoking peers may obstruct the formation of a generation with a smoke-free identity despite policy changes. Those born in 1997 and 1998 had reached the age of 15 and 14 years in 2012, and, as 'first impressions matter,' those who had been exposed for as long as a decade to schools where teachers and visitors smoked freely may have already established a norm about smoking before the time when complete bans were implemented. The gap between the younger, non-smoking generation and the relatively older, smoking generation can trigger a 'norm cascade ${ }^{37}$ or the view of smoking as an outdated concept. ${ }^{38}$

The marked reduction in smoking initiation rate, and the small increase in smoking cessation after the implementation of smoke-free legislation, demonstrate that cohort effects can influence adolescents to avoid ever trying a cigarette. Thus, positive results in terms of the reduction of smoking prevalence can be expected following the proposal for a tobacco-free generation ${ }^{38}$ which restricts tobacco sales and supply to adolescents by birth year to prevent smoking initiation.

It is intriguing that higher risks of smoking were found among adolescents who were only exposed to smoke-free legislation in their latter school years. Although additional work is required before an understanding of this phenomenon, speculations can be made based on previous studies. First, policies designed to restrict certain behaviours, such as the ban on smoking in public places, can backfire in adolescents due to arousal of a motivation to regain behavioural freedom, ${ }^{39}$ particularly when considering the inherently rebellious nature of this group. Second, the onset of early puberty, which is associated with higher risks of smoking, ${ }^{40}$ is more common among recent cohorts. For example, early menarche in girls increased from $17.2 \%$ for those born in 1988 to $24.6 \%$ for those born in $1998 .^{41}$ Third, the behaviour of these cohorts may have been influenced by macroenvironmental events. The severe economic crisis in 1997, and its aftermath, could have reduced parenting quality, increasing the risk of smoking among children. ${ }^{42}$ Furthermore, tobacco sales were at a record high of 5.3 billion packs in 1997, where sale statistics started being documented in $1985 .^{43}$

From our results, we recommend the use of birth year-specific statistics to examine cohort effects in smoking behaviour, in addition to the age-specific or year-specific statistics used conventionally in such studies. Furthermore, future research should focus on defining the characteristics and determinants of a generation where tobacco is greyed out, together with investigating the process of accepting this generational identity and the potential resistance to the initial implementation of tobacco control policies.

This study is subject to limitations. First, only speculations can be made about the dynamics of the observed changes due to the ecological design and descriptive nature inherent in the APC model. Still, APC models can provide valuable insight about macroenvironmental factors inducing temporal changes. Second, the study may not represent all adolescents in South Korea as participants of the survey were limited to those attending school. Nevertheless, less than $2 \%$ of people aged $12-17$ years were reported not to be enrolled in school. ${ }^{16}$ In addition, the study relied on self-reported measures of tobacco use rather than biochemically verified measures. Self-reporting of tobacco use by 
adolescents can result in under-reporting; however, the estimates of self-reported smoking in the KYRBS exhibited good validity when compared with urine cotinine estimates. ${ }^{44}$

In conclusion, our study demonstrates that smoke-free legislation is associated with substantial declines in smoking prevalence among adolescents. More importantly, the changes in smoking prevalence from generation to generation indicate that tobacco control policies can create social norms in which smoking is viewed as an outdated behaviour.

Discussions on attaining a tobacco-free generation have mostly centred on legislative measures, such as restricting tobacco sales and supply by birth year. ${ }^{38}$ However, generational norm against tobacco can be constructed through establishing a 'collective consciousness ${ }^{10}$ of tobacco use as an unacceptable behaviour, in addition to legislative measures, as exemplified by the presence of cohort effects reducing smoking among South Korean adolescents during the past decade. More research on norm-changing tobacco control measures is still required.

What this paper adds

- With the introduction and strengthening of tobacco control measures, smoking among adolescents has declined substantially worldwide over recent years.

- Knowledge on the specific types of tobacco control measures that can effectively reduce the prevalence of smoking among adolescents via cohort effects is limited.

- Implementation of legislation to make public places smoke-free may have led to a tobacco-free identity among the current generation of adolescents, which could have mitigated the positive association between age and smoking prevalence in adolescents.

- Cohort effects generated by tobacco control policies have contributed considerably to declines in cigarette smoking prevalence.

Contributors HK conducted the analyses and contributed to the drafting of the manuscript. S-iC advised on the data analyses. All authors designed the study, interpreted the findings, reviewed and approved the final version of the manuscript.

Funding The authors have not declared a specific grant for this research from any funding agency in the public, commercial or not-for-profit sectors.

Competing interests None declared.

Patient consent for publication Not required.

Ethics approval Seoul National University Institutional Review Board.

Provenance and peer review Not commissioned; externally peer reviewed.

Open access This is an open access article distributed in accordance with the Creative Commons Attribution Non Commercial (CC BY-NC 4.0) license, which permits others to distribute, remix, adapt, build upon this work non-commercially, and license their derivative works on different terms, provided the original work is properly cited, appropriate credit is given, any changes made indicated, and the use is non-commercial. See: http://creativecommons.org/licenses/by-nc/4.0/.

\section{ORCID iD}

Heewon Kang http://orcid.org/0000-0002-1519-5678

\section{REFERENCES}

1 Sanchez ZM, Prado MC, Sanudo A, et al. Trends in alcohol and tobacco use among Brazilian students: 1989 to 2010. Rev Saude Publica 2015;49:70.

2 US Department of Health and Human Services. Preventing tobacco use among youth and young adults: a report of the surgeon general. Atlanta, GA: US Department of Health and Human Services, Centers for Disease Control and Prevention, Office on Smoking and Health, 2012.

3 Lavack AM. De-normalization of tobacco in Canada. Soc Mar Q 1999:5:82-5.

4 Hammond D, Fong GT, Zanna MP, et al. Tobacco denormalization and industry beliefs among smokers from four countries. Am J Prev Med 2006;31:225-32.

5 Alamar B, Glantz SA. Effect of increased social unacceptability of cigarette smoking on reduction in cigarette consumption. Am J Public Health 2006;96:1359-63.
6 Gilpin EA, Lee L, Pierce JP. Changes in population attitudes about where smoking should not be allowed: California versus the rest of the USA. Tob Control 2004;13:38-44.

7 Malone RE, Grundy Q, Bero LA. Tobacco industry denormalisation as a tobacco control intervention: a review. Tob Control 2012;21:162-70.

8 Hellman M, Hakkarainen P, Sæbø G. Underpinnings of tobacco policy: an epistemic governance perspective. Concepts of addictive substances and behaviours across time and place 2016:151.

9 Ryder NB. The cohort as a concept in the study of social change. Cohort analysis in social research: Springer, 1985:9-44.

10 Mannheim K. The problem of generations. Psychoanalytic review 1970;57:378-404

11 Choi S, Kim Y, Lee J, et al. Tobacco use among students aged 13-15 Years in South Korea: The 2013 Global Youth Tobacco Survey. J Prev Med Public Health 2017:50:60-5

12 Debiasi-enrico E. Age-period-cohort analysis: a summary of analytical approaches and results.

13 Carpenter C, Cook PJ. Cigarette taxes and youth smoking: new evidence from national, state, and local Youth Risk Behavior Surveys. J Health Econ 2008:27:287-99.

14 Hawkins SS, Bach N, Baum CF. Impact of tobacco control policies on adolescent smoking. J Adolesc Health 2016;58:679-85

15 Katikireddi SV, Der G, Roberts C, et al. Has childhood smoking reduced following smoke-free public places legislation? A segmented regression analysis of crosssectional UK school-based surveys. Nicotine Tob Res 2016:18:1670-4

16 Kim Y, Choi S, Chun C, et al. Data resource profile: the Korea Youth Risk Behavior Web-based Survey (KYRBS). Int J Epidemiol 2016:43:dyw070-6.

17 Wagner AK, Soumerai SB, Zhang F, et al. Segmented regression analysis of interrupted time series studies in medication use research. J Clin Pharm Ther 2002;27:299-309.

18 StataCorp. Stata Statistical Software: Release 15. College Station, TX: StataCorp LLC, 2017.

19 Yang Y, Land KC. Age-period-cohort analysis: new models, methods, and empirical applications. Chapman and Hall/CRC, 2016.

20 Lutz W. Demographic metabolism: a predictive theory of socioeconomic change. Popul Dev Rev 2013:38:283-301.

21 O'Brien R. Age-period-cohort models: approaches and analyses with aggregate data: Chapman and Hall/CRC, 2014

22 R Core Team. R: A language and environment for statistical computing. Vienna, Austria: R Foundation for Statistical Computing, 2017

23 Wakefield M, Forster J. Growing evidence for new benefit of clean indoor air laws: reduced adolescent smoking: BMJ Publishing Group Ltd, 2005.

24 Wakefield MA, Chaloupka FJ, Kaufman NJ, et al. Effect of restrictions on smoking at home, at school, and in public places on teenage smoking: cross sectional study. BMJ 2000:321:333-7.

25 Bernat DH, Erickson DJ, Shi Q, et al. Short-term effects of a comprehensive, statewide smokefree law on perceived opportunities to smoke. Am J Prev Med 2010;39:S23-9.

26 Hamilton WL, Biener L, Brennan RT. Do local tobacco regulations influence perceived smoking norms? Evidence from adult and youth surveys in Massachusetts. Health Educ Res 2008:23:709-22.

27 Hwang JH, Park S-W. Smoking Cessation Intention according to the Level of Cigarette Price Increase among Adolescent Smokers. Journal of the Korean Society of School Health 2014;27:59-68.

28 Hwang JH, Park S-W. Is there differential responsiveness to a future cigarette price increase depending on adolescents' source of cigarette access? Medicine 2017;96:e7311.

29 Ministry of Education, Ministry of Health and Welfare, Korea Centers for Disease Control and Prevention. The Eleventh(2015) Korea Youth Risk Behavior Web-based Survey. Osong: Korea Centers for Disease Control and Prevention, 2015.

30 Chen X, Lin F, Stanton B, et al. APC modeling of smoking prevalence among US adolescents and young adults. Am J Health Behav 2011:35:416-27.

31 Kann L, McManus T, Harris WA, et al. Youth risk behavior surveillance-United States, 2015. Morbidity and Mortality Weekly Report: Surveillance Summaries 2016:65:1-174

32 Nelson DE, Mowery P, Asman K, et al. Long-term trends in adolescent and young adult smoking in the United States: metapatterns and implications. Am J Public Health 2008;98:905-15

33 Eisenberg ME, Forster JL. Adolescent smoking behavior: measures of social norms. Am J Prev Med 2003;25:122-8.

34 Young HP. The evolution of social norms. Economics 2015;7:359-87.

35 Ministry of Education, Ministry of Health and Welfare, Korea Centers for Disease Control and Prevention. The Thirteenth(2017) Korea Youth Risk Behavior Web-based Survey. Osong: Korea Centers for Disease Control and Prevention, 2017.

36 Park S. [Smoking behavior and predictors of smoking initiation in childhood and early adolescence]. J Korean Acad Nurs 2009;39:376-85.

37 Sunstein CR. Social norms and social roles. Columbia Law Rev 1996;96:903-68.

38 Berrick AJ. The tobacco-free generation proposal. Tob Control 2013;22(Suppl 1):i22-i26 


\section{Original research}

39 Kinzig AP, Ehrlich PR, Alston L, et al. Social norms and global environmental challenges: the complex interaction of behaviors, values, and policy. Bioscience 2013;63:164-75.

40 Westling E, Andrews JA, Peterson M. Gender differences in pubertal timing, social competence, and cigarette use: a test of the early maturation hypothesis. J Adolesc Health 2012;51:150-5.

41 Han D, Lee J, Kim S. Secular Trends and Influencing Factors for the Early Menarche among Korean Middle and High School Girls. The Journal of the Korea Contents Association 2016:16:319-27.
42 Ramanathan S, Balasubramanian N, Krishnadas R. Macroeconomic environment during infancy as a possible risk factor for adolescent behavioral problems. JAMA Psychiatry 2013;70:218-25.

43 Ministry of the Interior and Safety. Statistical yearbook of local tax. Sejong: Ministry of the Interior and Safety 1985-2016.

44 Korea Centers for Disease Control and Prevention. Reliability and validity of the korea youth risk behavior web-based survey questionnaire. Osong: Korea Centers for Disease Control and Prevention, 2009. 